\title{
Involvement of Spinal IL-6 Trans-Signaling in the Induction of Hyperexcitability of Deep Dorsal Horn Neurons by Spinal Tumor Necrosis Factor-Alpha
}

\author{
Christian König, ${ }^{1}$ Eric Morch, ${ }^{1}$ Annett Eitner, ${ }^{1}$ Christian Möller, ${ }^{1}$ Brian Turnquist, ${ }^{2}$ Hans-Georg Schaible, ${ }^{1}$ \\ and Andrea Ebersberger ${ }^{1}$ \\ ${ }^{1}$ Department of Physiology I/Neurophysiology, Jena University Hospital, Friedrich-Schiller-University of Jena, 07743 Jena, Germany, and ${ }^{2}$ Department of \\ Math and Computer Science, Bethel University, St. Paul, Minnesota 55112
}

During peripheral inflammation, both spinal TNF- $\alpha$ and IL-6 are released within the spinal cord and support the generation of inflammation-evoked spinal hyperexcitability. However, whether spinal TNF- $\alpha$ and IL-6 act independently in parallel or in a functionally dependent manner has not been investigated. In extracellular recordings from mechanonociceptive deep dorsal horn neurons of normal rats in vivo, we found that spinal application of TNF- $\alpha$ increased spinal neuronal responses to mechanical stimulation of knee and ankle joints. This effect was significantly attenuated by either sgp130, which blocks IL-6 trans-signaling mediated by IL-6 and its soluble receptor IL-6R (sIL-6R); by an antibody to the IL-6 receptor; or by minocycline, which inhibits the microglia. IL-6 was localized in neurons of the spinal cord and, upon peripheral noxious stimulation in the presence of spinal TNF- $\alpha$, IL- 6 was released spinally. Furthermore, TNF- $\alpha$ recruited microglial cells to provide sIL-6R, which can form complexes with IL-6. Spinal application of IL-6 plus sIL-6R, but not of IL-6 alone, enhanced spinal hyperexcitability similar to TNF- $\alpha$ and the inhibition of TNF- $\alpha$-induced hyperexcitability by minocycline was overcome by coadministration of sIL-6R, showing that sIL-6R is required. Neither minocycline nor the TNF- $\alpha$-neutralizing compound etanercept inhibited the induction of hyperexcitability by IL-6 plus sIL-6R. Together, these data show that the induction of hyperexcitability of nociceptive deep dorsal horn neurons by TNF- $\alpha$ largely depends on the formation of IL-6/sIL-6R complexes that are downstream of TNF- $\alpha$ and requires the interactions of neurons and microglia orchestrated by TNF- $\alpha$.

Key words: central sensitization; cytokine; electrophysiology; inflammation; microglia; soluble IL-6 receptor

Significance Statement

Both spinal TNF- $\alpha$ and IL-6 induce a state of spinal hyperexcitability. We present the novel finding that the full effect of TNF- $\alpha$ on the development of spinal hyperexcitability depends on IL- 6 trans-signaling acting downstream of TNF- $\alpha$. IL- 6 trans-signaling requires the formation of complexes of IL-6 and soluble IL- 6 receptor. Spinal TNF- $\alpha$ furthers the release of IL- 6 from neurons in the spinal cord during peripheral noxious stimulation and recruits microglial cells to provide soluble IL-6 receptor, which can form complexes with IL-6. Therefore, a specific interaction between neurons and microglia is required for the full development of TNF- $\alpha$-induced hyperexcitability of nociceptive deep horsal horn neurons.

\section{Introduction}

The proinflammatory cytokines TNF- $\alpha$ and IL- 6 are widely expressed in the CNS and fulfill numerous physiological and

\footnotetext{
Received Nov. 19, 2015; revised June 28, 2016; accepted July 21, 2016.

Author contributions: C.K., A. Eitner, H.-G.S., and A. Ebersberger designed research; C.K., E.M., A. Eitner, C.M., and A. Ebersberger performed research; B.T. contributed unpublished reagents/analytic tools; C.K., E.M., A. Eitner, C.M., B.T., H.-G.S., and A. Ebersberger analyzed data; C.K., H.-G.S., and A. Ebersberger wrote the paper.

This work was supported by the Bundesministerium für Bildung und Forschung (BMBF program Neuroimpa) and the Deutsche Forschungsgemeinschaft (DFG). We thank Konstanze Ernst and Jana Struppert for excellent technical assistance. The authors declare no competing financial interests.

Correspondence should be addressed to Dr. Andrea Ebersberger, Department of Physiology I/Neurophysiology, Jena University Hospital, Friedrich-Schiller-University of Jena, Teichgraben No.8, D-07743 Jena, Germany. E-mail: Andrea.Ebersberger@med.uni-jena.de.
}

pathophysiological functions (Erta et al., 2012; Santello and Volterra, 2012; Rothaug et al., 2016). In the spinal cord, TNF- $\alpha$ and IL-6 were particularly implicated in the spinal mechanisms of neuropathic (Marchand et al., 2005; Latrémolière et al., 2008; Milligan and Watkins, 2009) and inflammatory pain (Bao et al., 2001; Raghavendra et al., 2004; Vazquez et al., 2012; König et al., 2014). Spinal cytokines are released from activated glial cells (McMahon and Malcangio, 2009), but IL-6 is also produced by neurons (Cao and Zhang, 2008; Erta et al., 2012). 
The development of peripheral inflammation generates spinal hyperexcitability. This process of central sensitization causes an amplification and spreading of pain (Woolf and Salter, 2000). Recently, we found that both spinal TNF- $\alpha$ and IL-6 signaling are involved in the generation of spinal hyperexcitability evoked by developing inflammation in the joint. Spinal application of etanercept, which neutralizes TNF- $\alpha$, or of an antibody to the TNF receptor TNFR1 significantly attenuated the generation of spinal hyperexcitability during the development of peripheral inflammation (König et al., 2014). Similarly, spinal application of soluble gp130 (sgp130), which inhibits IL-6 trans-signaling (see below), attenuated the development of spinal hyperexcitability upon peripheral inflammation (Vazquez et al., 2012). Conversely, spinal application of either TNF- $\alpha$ or IL-6, together with its soluble receptor sIL-6R, enhanced the responses of nociceptive spinal cord neurons to innocuous and noxious mechanical stimulation of the knee joint (Vazquez et al., 2012; König et al., 2014).

A crucial question is whether these cytokines act independently or if their actions are connected functionally. Preliminary experiments indicated that the effects of TNF- $\alpha$ and IL-6/sIL-6R complexes on the neuronal responses are not additive, raising the possibility that their actions are crucially linked. TNF- $\alpha$ activates membrane-bound receptors TNFR1 and TNFR2. IL-6 signaling in cells is mediated by the activation of the transmembranesignal-transducing subunit glycoprotein 130 (gp130), which is expressed ubiquitously. To activate gp130, IL-6 can either bind to membrane-bound IL-6 receptor (gp80) or form a complex with sIL-6R and IL-6/sIL-6R complexes then activate gp 130. The latter process is called trans-signaling because it allows IL-6 signaling in cells that do not express membrane-bound gp80. IL-6/sIL-6R complexes are neutralized by sgp 130 , thus preventing the activation of gp130 (Jostock et al., 2001). Interestingly, endogenous sgp130 is present at high concentrations in blood and CSF (Padberg et al., 1999). Therefore, IL-6 trans-signaling is only possible if the concentration of IL-6/sIL-6R complexes overcomes the neutralization by sgp 130. Conversely, an excess of sgp130, as provided by exogenous sgp130, prevents trans-signaling (Nowell et al., 2003; Rose-John, 2012). IL-6 is either produced by neurons or glial cells (Erta et al., 2012), whereas an endogenous source of sIL-6R could be the microglia-expressing gp80 (Hsu et al., 2015). Proteases capable of shedding gp80, such as ADAM10/17, are widely expressed (Garbers et al., 2011). Therefore, a cooperative action of neurons and glial cells may be a requisite for IL-6 signaling. This question is of major interest because many pain states, including those of arthritis and osteoarthritis, are characterized by glial activation and cytokine involvement (Clark et al., 2007; Milligan and Watkins, 2009; Christianson et al., 2010; Sagar et al., 2011; Ji et al., 2013).

In the present experiments, we investigated whether the sensitizing effects of TNF- $\alpha$ and IL- 6 signaling depend on each other. We performed electrophysiological recordings from spinal cord neurons in vivo, which allowed us to apply agonists and neutralizing compounds to the spinal cord surface at the recording site. Furthermore, we measured the release of mediators in vivo and used a microglial cell line and primary microglia to address specific questions on the effects of cytokines on glial cells. Our findings suggest that spinal TNF- $\alpha$ sensitizes spinal cord neurons, mainly by activating spinal IL$6 /$ sIL-6R signaling, and this depends on the cooperation of neurons and glial cells.

\section{Materials and Methods}

Animals. Adult male Wistar rats $(n=95,250-450 \mathrm{~g})$ were housed under $12 \mathrm{~h} / 12 \mathrm{~h} \mathrm{light/dark}$ conditions in a temperature-controlled environment with ad libitum food and water. The study was approved by the Thuringian Government (Reg. No. 02-008/13) and experiments were performed in accordance with the Animals Protection Act of the Federal Republic of Germany. For primary cell cultures, C57/B6J mice were housed under the same conditions.

Recordings from spinal cord neurons. Rats were deeply anesthetized with sodium thiopental (Trapanal, 100-120 mg/kg, i.p.; Rotexmedica). The trachea was cannulated and a gentle jet of oxygen was blown toward the cannula to assist respiration. Catheters filled with Tyrode's solution containing the following (in mM): $140 \mathrm{NaCl}, 2.7 \mathrm{KCl}, 2.4 \mathrm{CaCl}_{2}, 2.3$ $\mathrm{MgCl}_{2}, 12 \mathrm{NaHCO}_{3}$, and $0.24 \mathrm{NaH}_{2} \mathrm{PO}_{4}, \mathrm{pH} 7.4$, and 12.5 or 1 units heparin (Heparin-Natrium-25000; Ratiopharm) were inserted into the carotid artery to measure mean arterial blood pressure (usually $\sim 100 \pm$ $20 \mathrm{mmHg}$ ) and into the jugular vein. Body temperature was kept at $37^{\circ} \mathrm{C}$ using a feedback-controlled thermostat. As necessary, additional injections of sodium thiopental were applied $(12 \mathrm{mg} / \mathrm{kg}$, i.p.) to maintain a deep level of anesthesia, which was characterized by a stable blood pressure during noxious stimulation and the absence of corneal reflexes.

The animal was fixed in a frame and lumbar segments L1-L4 were exposed by laminectomy. The dura mater was opened. The surgical area was stabilized with $3 \%$ agar in Tyrode's solution, leaving uncovered a tightly sealed trough $(3 \times 5 \mathrm{~mm})$ on the surface of the spinal cord, which was immediately filled with $\sim 50 \mu \mathrm{l}$ of Tyrode's solution to avoid drying of the tissue.

Extracellular recordings from individual neurons with input from the knee joint were performed with glass-insulated carbon filaments. For data collection, neurons were selected that responded to pressure applied to the ipsilateral left knee but did not respond to stroking and squeezing of the overlying skin. Action potentials of a neuron were monitored continuously on a digital oscilloscope and saved on PC for final offline spike analysis using Dapsys version 8.42 software (Turnquist et al., 2004).

For mechanical testing, mechanical stimuli were applied to the mediolateral axis of the knee with a manometer (Correx) at innocuous (1.9 $\mathrm{N} / 40 \mathrm{~cm}^{2}$ ) and noxious ( 7.8 or $5.9 \mathrm{~N} / 40 \mathrm{~cm}^{2}$ ) intensity. Thereafter, the ankle and the paw were stimulated with defined clamps (innocuous: 1.1 $\mathrm{N} / 20 \mathrm{~cm}^{2}$, noxious: $5.8 \mathrm{~N} / 20 \mathrm{~cm}^{2}$, respectively). Each stimulus lasted for $15 \mathrm{~s}$, followed by $15 \mathrm{~s}$ without stimulation. The whole stimulation circle was repeated every $5 \mathrm{~min}$.

All recordings started by repetition of the stimulation sequence until stable responses of the neurons were obtained. According to experimental protocols, recombinant rat TNF- $\alpha$ (ImmunoTools), recombinant rat IL-6 (Life Technologies), recombinant sgp130, recombinant human IL-6, and/or recombinant human sIL-6R (R\&D Systems) were then applied directly in Tyrode's solution onto the spinal cord surface into the trough over the recording site at a concentration of $1 \mu \mathrm{g} / \mathrm{ml}$. In seven experiments, a neutralizing anti-IL-6R antibody (at $5 \mu \mathrm{g} / \mathrm{ml}$ ) that binds to sIL-6R and gp80 of rat (catalog \#115807; BioLegend; see also Walker et al., 2008) was applied and purified rat IgG2b, $\kappa$ isotype control (catalog \#400621; BioLegend) at 5 $\mu \mathrm{g} / \mathrm{ml}$ was applied as a control. Etanercept (Enbrel; Pfizer) was coapplied in selected experiments at $12.5 \mu \mathrm{g} / \mu \mathrm{l}$. In other experimental groups, the baseline responses were established, minocycline ( $1 \mu \mathrm{g} / \mathrm{ml}$; Sigma-Aldrich) was applied onto the spinal cord, and stimulation and recording were continued for $1 \mathrm{~h}$. Next, combinations of minocycline and a test substance (see above) were applied for another $2 \mathrm{~h}$.

For data analysis, action potentials were evaluated offline by shape and amplitude using Dapsys version 8.42 software. The action potentials during each stimulus application ( $15 \mathrm{~s}$ ) were counted. Mean neuronal responses to a stimulus of consecutive time intervals of $30 \mathrm{~min}$ were compared with a 30 min baseline before application of substances.

Measurement of IL-6 in spinal supernatants. In rats in which supernatants from the spinal cord were collected, a spinal trough with a capacity of $120-140 \mu \mathrm{l}$ was used. Tyrode's solution $(120 \mu \mathrm{l})$ was filled into the spinal trough and completely redrawn after the indicated time points (see Fig. $2 A$ ) and immediately frozen at $-20^{\circ} \mathrm{C}$. Samples were finally processed with a commercial enzyme immunoassay for rat IL-6 (catalog 
\#550319, BDset OptEIA; eBiosciences) and using a Tecan plate reader with Magellan 3.0 software at $450 \mathrm{~nm}$.

Measurement of sIL-6R in BV2 microglia cell culture supernatants and preparations of primary mouse microglia. Mouse BV2 microglia cells (kind gift from Reinhard Bauer, Center for Molecular Biomedicine, Institute of Molecular Biology, Jena, Germany) were seeded at $5 \times 10^{4}$ cells/well into 12 -well plates (Thermo Scientific) and cultivated in Dulbecco's modified Eagle's medium (DMEM; Lonza) containing 10\% heat-inactivated fetal bovine serum (BioWest) for $24 \mathrm{~h}$. After washing the cells with pure DMEM, cells were stimulated with recombinant mouse TNF- $\alpha$ and recombinant mouse IL-6 (100 ng/ml each; ProSpec) in DMEM for $2 \mathrm{~h}$. For minocycline treatment, the inhibitor was applied at $1 \mu \mathrm{g} / \mathrm{ml}$ in DMEM for $30 \mathrm{~min}$ before stimulation and was constantly present during the cytokine stimulation. After $2 \mathrm{~h}$, supernatants were collected and immediately frozen on dry ice. Six independent experiments were performed in duplicate.

Newborn mice [postnatal day 1 (P1)-P3] were decapitated and whole brains were collected in Dulbecco's PBS (D-PBS; Life Technologies). After removal of meninges, cortices were separated and minced with a scalpel and transferred to DMEM containing freshly supplied $2.5 \mathrm{mg} / \mathrm{ml}$ Trypsin/EDTA (PAA) and $3.5 \mu \mathrm{g} / \mathrm{ml}$ DNase (Sigma-Aldrich) and incubated for $20 \mathrm{~min}$ at $37^{\circ} \mathrm{C}$. Cortices were gently triturated with a firepolished Pasteur pipette and transferred to cell culture flasks (Greiner) with DMEM supplemented with $10 \%$ heat-inactivated fetal bovine serum (BioWest) and 1\% penicillin/streptomycin (Lonza). After $7 \mathrm{~d}$, half of the medium was refreshed. After observing a confluent astrocyte layer, top-adhering microglia cells were shaken off at $500 \mathrm{rpm}$ for $3 \mathrm{~h}$ at $37^{\circ} \mathrm{C}$. The suspension harvested from one flask was separated equally and seeded into two wells of a 48-well plate (Greiner). After $24 \mathrm{~h}$ of culture, microglial cells were stimulated with $100 \mathrm{ng} / \mathrm{ml}$ recombinant mouse TNF- $\alpha$ (ProSpec) in pure DMEM for $2 \mathrm{~h}$. The supernatants were collected and immediately frozen on dry ice. To monitor the purity of microglia, aliquots of harvested cells were seeded on poly-L-lysine (Sigma-Aldrich)-coated coverslips, fixed, and stained with rabbit antiIba1 (catalog \#019-19741; Wako Chemicals) or rabbit anti-GFAP (catalog \#18-0063; Life Technologies) detected with goat anti-rabbit coupled to Alexa Fluor 488 (Life Technologies) always in the presence of DAPI (Sigma-Aldrich) staining.

ELISA for mouse sIL-6R (catalog \#rab0314; Sigma-Aldrich) was performed following the manufacturer's instructions and optical density was measured at $450 \mathrm{~nm}$ using a Tecan plate reader.

Immunohistochemistry on rat spinal cord tissue. Rats were deeply anesthetized with sodium thiopental $(\sim 200 \mathrm{mg} / \mathrm{kg}$, i.p.) and transcardially perfused with ice-cold $4 \%(w / v)$ paraformaldehyde (PFA) in PBS containing the following (in $\mathrm{mM}$ ): $140 \mathrm{NaCl}, 2.7 \mathrm{KCl}, 1.5 \mathrm{KH}_{2} \mathrm{PO}_{4}$, and 8.1 $\mathrm{NaH}_{2} \mathrm{PO}_{4}$. The lumbar spinal cord was removed, postfixed for $24 \mathrm{~h}$ in $4 \%$ PFA, dehydrated, and embedded in Technovit 9100 methyl methacrylate (Heraeus) according to the manufacturer's instructions. Sections of 4 $\mu \mathrm{m}$ thickness were cut using a Polycut S microtome (Reichert-Jung). To remove polymer, sections were treated with 2-methoxyethylacetate and rehydrated in decreasing concentrations of alcohol. For antigen retrieval, sections were autoclaved for $15 \mathrm{~min}$ in citric acid $\left(100 \mathrm{mM} \mathrm{C}_{6} \mathrm{H}_{8} \mathrm{O}_{7}, \mathrm{pH} 6\right)$ and then washed with TBS (Tris-buffered saline, $20 \mathrm{~mm}, \mathrm{pH} 7.6$ ) and incubated with blocking solution (TBS with $10 \%$ normal goat serum and $1 \%$ Triton X-100) for 30 min. Next, sections were incubated with the following primary antibodies: mouse anti-IL-6 monoclonal antibody (1: 250; catalog \#ab9324; Abcam) recognizing human, rat, and mouse IL-6 from the brain (see also Neher et al., 2013), rabbit anti-PGP9.5 (1:500; catalog \#7863-0504; AbD Serotec), rabbit anti-Iba1 (1:200; catalog \#01919741; Wako Chemicals), and rabbit anti-GFAP (1:100; catalog \#180063; Thermo Scientific) at $4^{\circ} \mathrm{C}$ overnight. For controls, primary antibodies were omitted. Secondary antibodies, conjugated with Alexa Fluor 488 or Alexa Fluor 568 (Life Technologies), were incubated for $2 \mathrm{~h}$ in the dark. After additional washing, sections were mounted with coverslips and ProLong Gold antifade reagent (Life Technologies). Immunostaining was detected using the confocal laser scanning microscope Leica TCS SP5.

Stimulation, SDS-PAGE, and Western blotting on BV2 and SH-SY5Y cells. Mouse BV2 microglia cells and human SH-SY5Y neuroblastoma cells (DSMZ) were seeded into 12-well plates and cultivated in DMEM with $10 \%$ heat-inactivated fetal bovine serum for $24 \mathrm{~h}$. Cells were washed and starved for $18 \mathrm{~h}$ in pure DMEM before stimulation.

For signaling analysis, BV2 cells were treated with $100 \mathrm{ng} / \mathrm{ml} \mathrm{recom-}$ binant mouse IL-6 and SH-SY5Y cells were treated with the complex of recombinant human IL-6 and sIL-6R ( $100 \mathrm{ng} / \mathrm{ml}$ each) for different time periods with or without the presence of $1 \mu \mathrm{g} / \mathrm{ml}$ minocycline. If used, minocycline was preincubated for $30 \mathrm{~min}$ before cytokine stimulation. The reaction was stopped on ice, medium was aspirated, and cells were scraped and harvested with RIPA lysis buffer containing the following (in mM): 20 Tris- $\mathrm{HCl}, 150 \mathrm{NaCl}, 2.5 \mathrm{Na}_{4} \mathrm{P}_{2} \mathrm{O}_{7}, 1$ EGTA, and 1 $\beta$-glycerophosphate, along with $1 \% \mathrm{C}_{24} \mathrm{H}_{39} \mathrm{NaO}_{4}$ and $1 \% \mathrm{NP}-40$, pH 7.4, freshly supplemented with protease inhibitor cocktail tablets (Roche). After a freeze-thaw cycle, cell lysates were centrifuged and $6 \times$ Laemmli loading buffer was added to supernatants.

For protein analysis, protein samples were separated on 10\% PAGEgels at $125 \mathrm{~V}$ and transferred to a PVDF membrane (Millipore). Immunoblotting followed with anti-Phospho-Stat3-Tyr705 (catalog \#9145; Cell Signaling Technology) and anti-Stat3 (catalog \#4904; Cell Signaling Technology). The signals were visualized with HRP-linked secondary antibodies (KPL) and an enhancing chemiluminescence reaction (Thermo Scientific) according to the manufacturer's instructions using a CCD camera system (Synoptics)

Statistics. In electrophysiological recordings in vivo, changes of responses within the groups were tested for significance with the Wilcoxon matched-pairs signed-rank test. Intergroup comparisons were calculated by Mann-Whitney $U$ tests. For multiple comparisons, Bonferroni correction was applied. For comparison of ELISA measurements of supernatants from spinal cord or cell culture, the Kolmogorov-Smirnov test was used, followed by $t$ tests (cell line) or Wilcoxon matched-pairs signed-rank test (primary cell culture). Statistics were calculated with SPSS. Significance was acknowledged if $p<0.05$.

\section{Results}

\section{Recording of neuronal activity}

We performed in vivo extracellular recordings from 90 nociceptive neurons with input from the knee joint in the deep dorsal horn of rats in a depth of $894 \pm 239 \mu \mathrm{m}$ (mean \pm SD) from the surface of the spinal cord. All selected neurons were activated by compression of the knee joint, but did not respond to brushing and squeezing the skin overlying the knee joint. Typically, these neurons were also activated by compression of the ankle joint and some of them were also activated by compression of the paw and muscle bellies of the thigh and lower leg. The sites for mechanical stimulation are shown in Figure $1 A$. Substances were applied locally at the recording site. In each animal, a single neuron was recorded.

\section{TNF- $\alpha$-induced spinal hyperexcitability and IL- 6 signaling}

To test whether the effect of TNF- $\alpha$ on the responses of spinal cord neurons to stimulation of the knee and the ankle is altered by interfering with IL-6 signaling, we applied either TNF- $\alpha$ or TNF- $\alpha$ plus sgp130 to the spinal cord surface. The compound sgp130 neutralizes IL-6/sIL-6R complexes and prevents IL-6 trans-signaling (Jostock et al., 2001). TNF- $\alpha$ caused a progressive increase of the responses to innocuous and noxious pressure onto the knee and the ankle joint, whereas such an increase was significantly smaller after spinal application of TNF- $\alpha$ plus sgp130. Figure $1 B$ displays the change of the responses from baseline (mean set zero) in periods of $30 \mathrm{~min}$; Figure $1 C$ shows the absolute numbers of action potentials of responses at baseline and 90-120 $\min (2 \mathrm{~h})$ after the application of TNF- $\alpha$ or TNF- $\alpha$ plus sgp130. Asterisks label significant increases compared with baseline; arrows indicate the first time period in which the responses were significantly different from baseline (Wilcoxon matchedpairs signed-rank test). Crosses indicate significant differences between groups (Mann-Whitney $U$ test). Similar to the experi- 
A
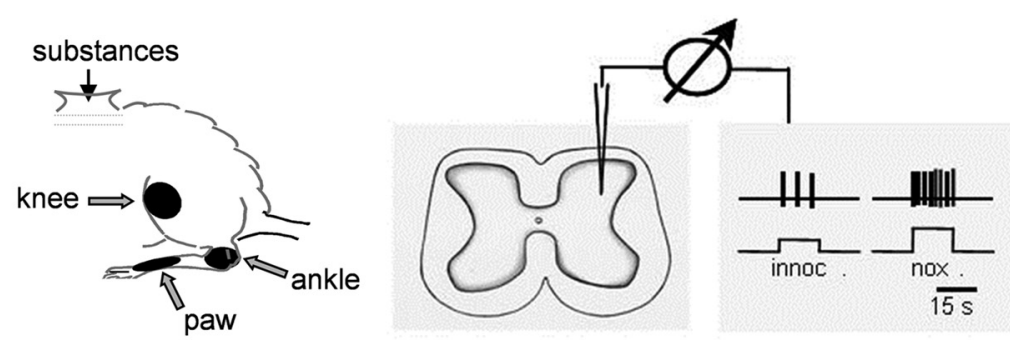

B

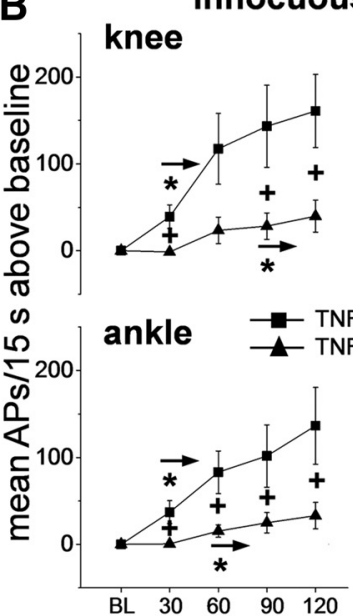

C

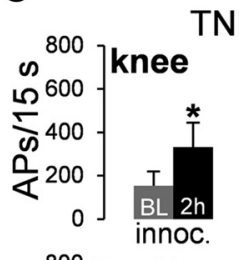

TNF- $\alpha$
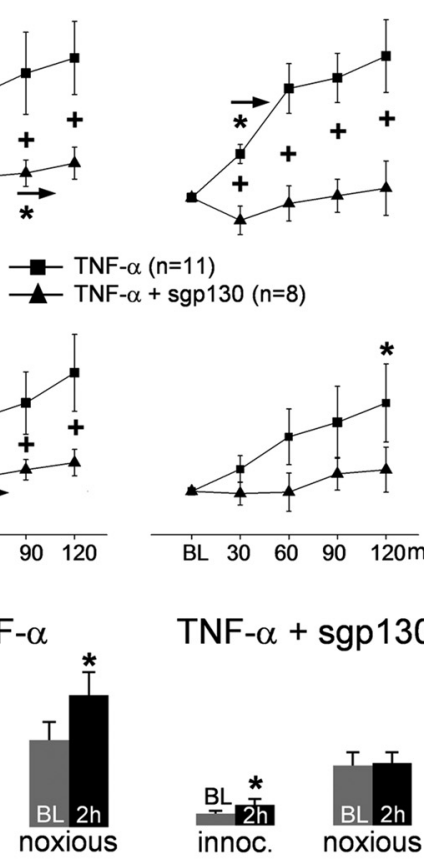

noxious

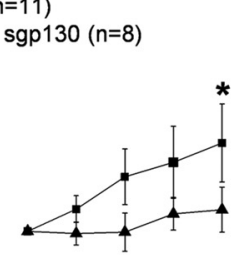

BL $\begin{array}{llll}30 & 60 & 90 & 120 \mathrm{~min}\end{array}$

TNF- $\alpha+\operatorname{sgp} 130$

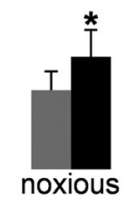

D

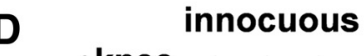

noxious

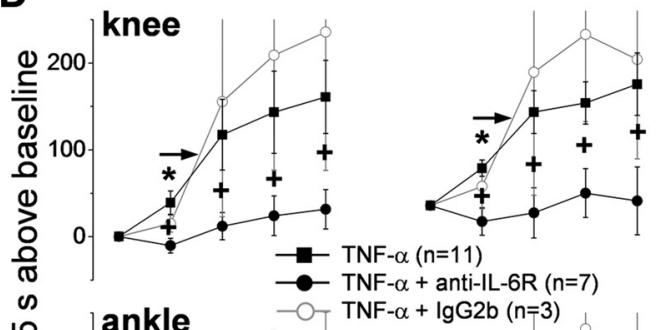

E

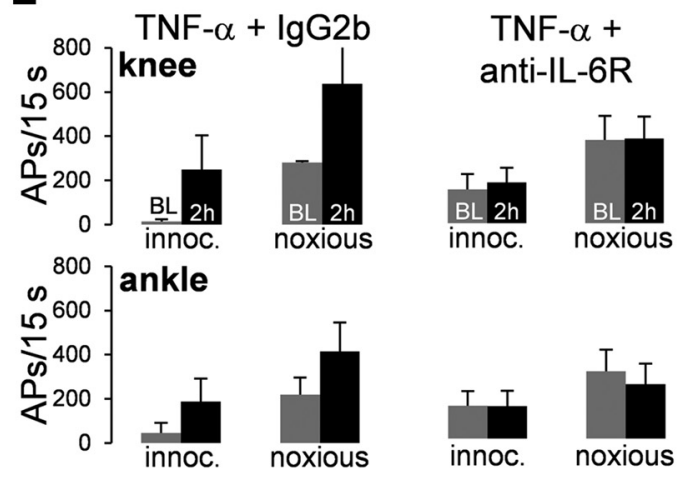

Figure 1. Recording of neuronal activity and reduction of TNF- $\alpha$-induced spinal hyperexcitability by sgp 130 or anti-IL-6R. A, Experimental setup. Responses of spinal cord neurons in the deep dorsal horn with knee and ankle input were recorded in vivo. Innocuous (innoc.) and noxious (nox.) pressure were applied to the knee, ankle, and paw. Each stimulus lasted for $15 \mathrm{~s}$, followed by $15 \mathrm{~s}$ without stimulation. Substances were applied to the surface of the spinal cord at the recording site. $\boldsymbol{B}$, Comparison of the increases of the neuronal responses to innocuous and noxious mechanical stimulation of the knee and ankle joints for $2 \mathrm{~h}$ after spinal application of TNF- $\alpha(n=11)$ or TNF- $\alpha$ plus sgp $130(n=8)$, shown as mean number of action potentials per $15 \mathrm{~s}$ (mean APs $/ 15 \mathrm{~s}) \pm$ SEM for intervals of $30 \mathrm{~min}$. The baseline (BL) responses before TNF- $\alpha$ or TNF- $\alpha$ plus sgp130 are set to zero. C, Comparison of the neuronal responses to innocuous and noxious knee and ankle stimulation in absolute values at baseline and $90-120 \mathrm{~min}(2 \mathrm{~h})$ after TNF- $\alpha$ treatment and TNF- $\alpha$ plus sgp 130 treatment. $\boldsymbol{D}$, Comparison of the increases of the neuronal responses to innocuous and noxious mechanical stimulation of the knee and ankle joints for $2 \mathrm{~h}$ after spinal application of TNF- $\alpha(n=11$, same as in $\boldsymbol{B})$ or TNF- $\alpha$ plus anti-IL-6R ( $n=7)$. The gray lines display the effect of TNF- $\alpha$ plus the isotype control antibody ( $n=3$, no statistics). $\boldsymbol{E}$, Comparison of the neuronal responses to innocuous and noxious knee and ankle stimulation in absolute values at baseline and $90-120 \mathrm{~min}(2 \mathrm{~h}$ ) after TNF- $\alpha$ plus anti-IL-6R and TNF- $\alpha$ plus $\lg \mathrm{G} 2 \mathrm{~b}$. In $\boldsymbol{B}$ and $\boldsymbol{D}$, asterisks with arrow indicate the start of a significant increase of responses or a significant increase of responses at the specific time points $(p<0.05$ by Wilcoxon matched-pairs signed-rank test); plus signs indicate significant difference between the groups at the specific time point $(p<0.05$ by Mann-Whitney $U$ test). In $C$, asterisks indicate a significant increase ( $p<0.05$, Wilcoxon matched-pairs signed-rank test).

mental group with coapplication of TNF- $\alpha$ and sgp130, only a small increase of the responses to stimuli was observed when TNF- $\alpha$ was coadministered with a neutralizing anti-IL-6R antibody that binds to sIL-6R and gp80 of rat (Fig. $1 D, E$; in Fig. $1 D$, the TNF- $\alpha$ group is the same as in Fig. $1 B$ ). In contrast, the coapplication of TNF- $\alpha$ with a purified rat IgG2b for control did not prevent the increase of the responses $(n=3$, gray lines in Fig. $1 D)$. The application of Tyrode's solution (vehicle) to the spinal cord did not enhance the spinal responses within $2 \mathrm{~h}(n=3$, data not shown). The data in Figure 1 show that the application of TNF- $\alpha$ to the spinal cord enhanced the responses to mechanical stimuli progressively and that this effect was attenuated significantly or even prevented by sgp130 or an anti-IL-6R antibody. Together, the data indicate that the generation of hyperexcitability of nociceptive deep dorsal horn neurons by TNF- $\alpha$ involves IL-6 signaling.

The effect of sgp130 suggests that TNF- $\alpha$ may act via the formation of complexes of IL- 6 and sIL-6R. Therefore, we tested first whether IL- 6 was released from the spinal cord during the experimental protocol shown in Figure $1 B$. We performed the standard protocol of mechanical stimulation, applied TNF- $\alpha$ after the recording of the baseline, removed the supernatants after 
A

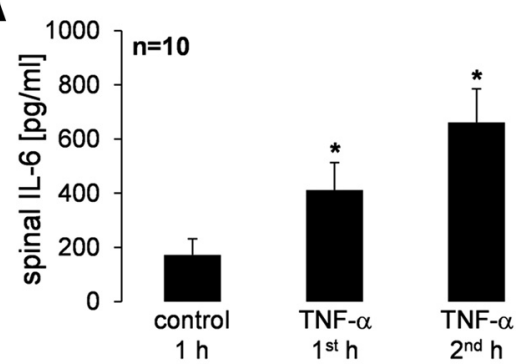

B

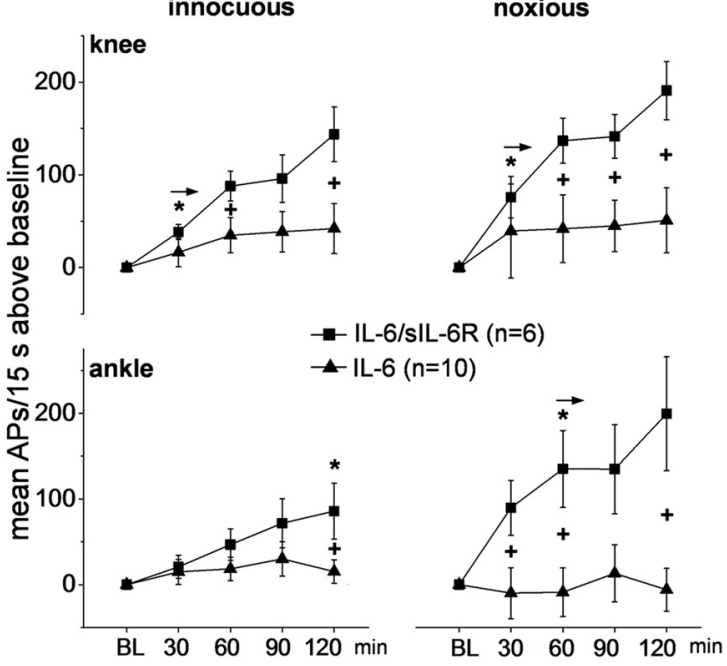

Figure 2. Increase of spinal IL-6 release during peripheral stimulation in the presence of spinally applied TNF- $\alpha$ and neuronal effects of IL-6 and IL-6/sIL-6R.A,Spinal IL-6release (means \pm SEM) into the spinal cord supernatant in the course of the stimulation protocol and spinal TNF- $\alpha$ application. Samples were extracted after $1 \mathrm{~h}$ of baseline (control) and 1 and $2 \mathrm{~h}$ after TNF- $\alpha$ application $(n=10)$. *Significant increase after TNF- $\alpha$ compared with control before TNF- $\alpha$ ( $p<0.05$ by $t$ test). $\boldsymbol{B}$, Increase of neuronal responses to knee and ankle stimulation after spinal application of $\mathrm{IL}-6(n=10)$ or of IL-6/IL-6 soluble receptor (sIL6-R, $n=6$ ) within $2 \mathrm{~h}$, shown as mean number of action potentials per $15 \mathrm{~s}$ (mean APs $/ 15 \mathrm{~s}$ ) \pm SEM for intervals of $30 \mathrm{~min}$. Baseline responses (in APs $/ 15 \mathrm{~s}$ ) in the IL-6 group: innocuous pressure knee $109.3 \pm 35.9$, noxious pressure knee $395.1 \pm 75.3$, innocuous pressure ankle 75.2 \pm 28.9 , noxious pressure ankle 483.0 \pm 126.0 . Baseline responses (in APs/15s) in the IL-6/sIL6-R group: innocuous pressure knee $154.5 \pm 23.2 \mathrm{APs} / 15 \mathrm{~s}$, noxious pressure knee $357.8 \pm 43.1$, innocuous pressure ankle $67.0 \pm 28.7$, noxious pressure ankle $470.4 \pm 80.7$. Asterisks with arrow indicate the start of significant increases of responses or significant increase of responses at the specific time point ( $p<0.05$ by Wilcoxon matched-pairs signed-rank test); plus signs indicate significant difference between the groups at the specific time point $(p<0.05$ by Mann-Whitney $U$ test). BL, Baseline.

1 and $2 \mathrm{~h}$ after TNF- $\alpha$, and measured the concentration of IL- 6 using an anti-rat IL-6 ELISA. Within $2 \mathrm{~h}$ after spinal application of TNF- $\alpha$, IL-6 levels increased up to fourfold (Fig. 2A). The concentration of IL- 6 accumulated within $1 \mathrm{~h}$ increased from $171.7 \pm 60.3 \mathrm{pg} / \mathrm{ml}$ (mean \pm SEM) before TNF- $\alpha$ to $661.6 \pm$ $123.4 \mathrm{pg} / \mathrm{ml}$ within the second hour.

In the next step, we tested whether spinal application of IL-6 mimics the TNF- $\alpha$-induced increase of neuronal responses. We used the standard protocol of mechanical stimulation and applied IL-6 after having established the baseline. As shown in Figure 2B, even a large dose of IL- 6 caused only a negligible and nonsignificant increase of the responses to mechanical stimulation. However, the application of both IL- 6 and sIL-6R caused an increase of the responses similar to TNF- $\alpha$. The IL- 6 group and the IL-6/sIL-6R group differed significantly at most time points. Therefore, although IL-6 is released after TNF- $\alpha$ application, it does not mimic the effect of TNF- $\alpha$ without adding sIL-6R. Therefore, if the TNF- $\alpha$ effect is mediated by IL-6/sIL-6R, as suggested by the prevention of the
TNF- $\alpha$ effect by sgp130, then there must be an endogenous source of sIL-6R.

Putative sources of IL-6 and sIL-6R in the spinal cord

According to the literature, IL- 6 can be produced by neurons or by glial cells (Erta et al., 2012). We used immunochemistry to study the expression of IL-6 in the spinal cord. Figure $3 A$ (with enlargements of regions in $A a$ and $A b$ ) shows the labeling of neurons with PGP9.5 (red) and the labeling for IL-6 (green). We found extensive colocalization of PGP9.5 and IL-6 (yellow). In contrast, only very sparse colabeling was found for microglial cells and IL-6 (Fig. 3B, red: Iba1-positive microglial cells, green: IL-6; note: due to the thickness of the sections of $4 \mu \mathrm{m}$, the microglial cells do not exhibit the typical pattern) and no costaining was found for GFAP-positive astroglia and IL-6 (Fig. 3C, red: GFAP, green: IL-6). Therefore, in the spinal cord of naive rats, IL-6 is mainly localized in neurons.

The source of sIL-6R in the CNS is restricted. Microglial cells express membrane-bound IL-6R (Rothaug et al., 2016) and endothelial cells of the cerebrovascular system respond well to IL-6 (Campbell et al., 2014; Hsu et al., 2015). To test whether microglia is a possible source of sIL-6R, we performed an anti-sIL-6R ELISA of six independent stimulation experiments on BV2 cells, a mouse microglial cell line that is a suitable model of microglia (Henn et al., 2009). We detected a basal release of sIL-6R (26.0 \pm $3.9 \mathrm{pg} / \mathrm{ml}$, mean $\pm \mathrm{SEM}$, within $2 \mathrm{~h}$ ). TNF- $\alpha$ increased the release of sIL-6R into the supernatant of the BV2 cells by, on average, $77 \%$ to $46.1 \pm 7.1 \mathrm{pg} / \mathrm{ml}(p<0.05, t$ test; Fig. $4 A)$. The presence of minocycline, a widely accepted inhibitor of microglia (Yrjänheikki et al., 1998; Garrido-Mesa et al., 2013), insignificantly reduced the basal release to $15.5 \pm 3.4 \mathrm{pg} / \mathrm{ml}$, but significantly inhibited the TNF- $\alpha$-induced sIL-6R release, which reached only $26.6 \pm 3.4 \mathrm{pg} / \mathrm{ml}(p<0.05, t$ test $)$. IL- 6 did not enhance the recruitment of its own soluble receptor $(21.1 \pm 3.1 \mathrm{pg} / \mathrm{ml}$, similar to the basal release). In microglial cells from primary microglial cell culture, the enhancement of the release of sIL-6R by TNF- $\alpha$ was confirmed. The microglial cells showed a basal release of sIL-6R $(15.1 \pm 3.8 \mathrm{pg} / \mathrm{ml})$ and TNF- $\alpha$ increased the release of sIL-6R by, on average, $52 \%$ to $24.1 \pm 7.2 \mathrm{pg} / \mathrm{ml}$ (Fig. $4 B$ ). The immunocytochemical specimens in Figure $4 B$ show that almost all cells in the culture were identified as Iba1-positive microglial cells (blue shows nuclear DAPI staining); only a very few were GFAP-positive. For quantification, cell numbers of five independent pictures from a coverslip either stained for Iba 1 or GFAP were counted using DAPI staining and the percentage of either Ibal-positive cells $(>90 \%)$ or GFAP-positive cells was determined.

Minocycline affects mainly microglia. IL-6-dependent signaling such as the acute phosphorylation of Stat 3 is strongly reduced by minocycline in the IL-6R-positive BV2 microglia cell line within $30 \mathrm{~min}$ (Fig. 4C, left). Stimulation of the IL-6R-negative neuronal cell line SH-SY5Y with the IL-6/sIL-6R complex also showed a strong phosphorylation of Stat3, illustrating the effect of IL-6 trans-signaling. However, the effect on neurons could not be prevented by minocycline (Fig. $4 C$, right). Together, the data show that the microglia are a source of sIL-6R and that TNF- $\alpha$ can mobilize sIL-6R from microglial cells.

Involvement of glial cells in the induction of hyperexcitability by TNF- $\alpha$

In the next step, we tested in vivo whether the effect of TNF- $\alpha$ on the neuronal responses is affected by minocycline. We used the standard stimulation protocol and, after assessment of the baseline 

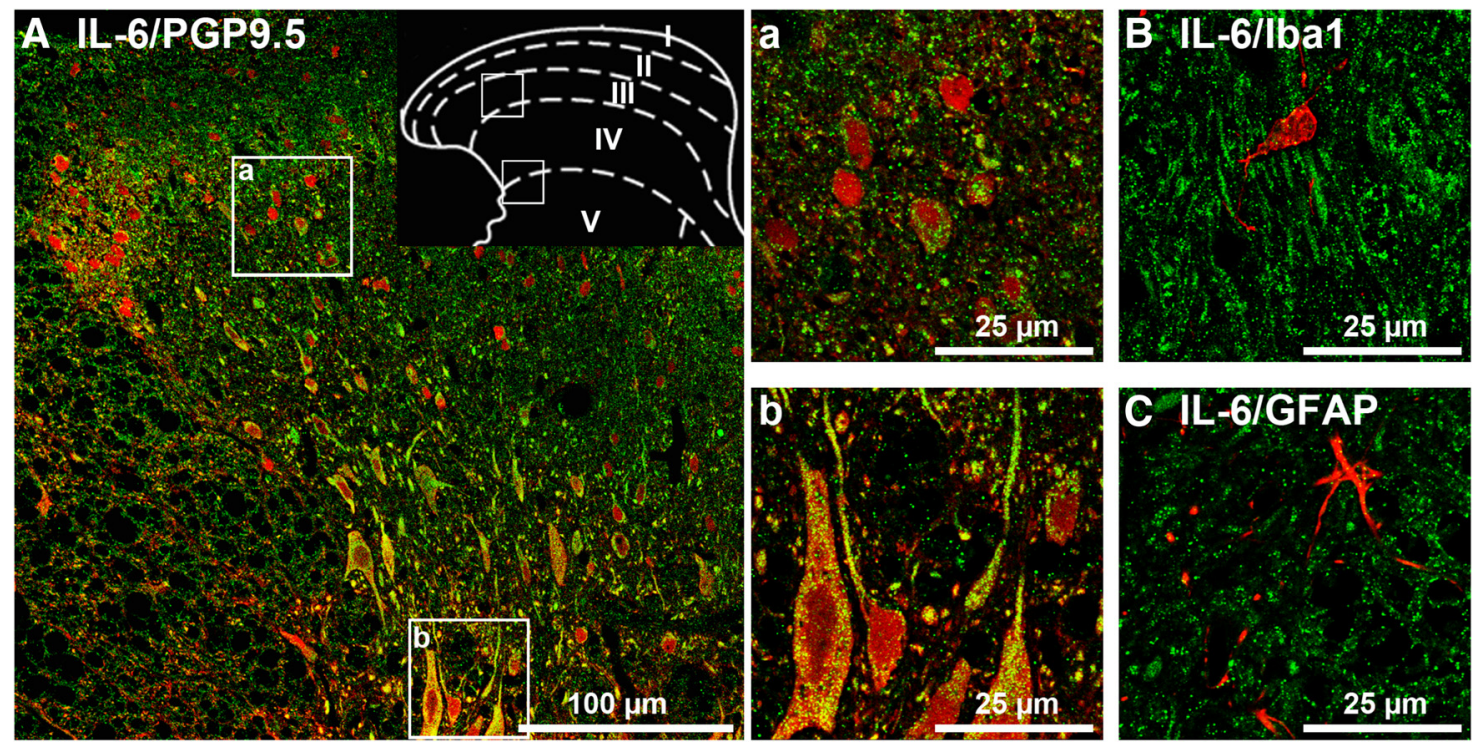

Figure 3. Immunostaining of the dorsal horn of the spinal cord of untreated rats for the localization of IL-6. A, Labeling of neurons with PGP9.5 (red) and labeling for IL-6 (green). Extensive colocalization of PGP9.5 and IL-6 (yellow) showing IL-6 in neurons. Enlargements of two regions (squares) are shown in $\boldsymbol{A} \boldsymbol{a}$ and $\boldsymbol{A} \boldsymbol{b}$. $\boldsymbol{B}$, Labeling of lba1-positive microglial cells (red) and labeling for IL-6 (green); there was only very sparse colabeling (yellow). Note: due to the thickness of the sections of $4 \mu \mathrm{m}$, the microglial cells do not exhibit the typical pattern. C, Labeling of GFAP-positive astroglia (red) and labeling for IL-6 (green). There was no costaining for GFAP-positive astroglia and IL-6.

A

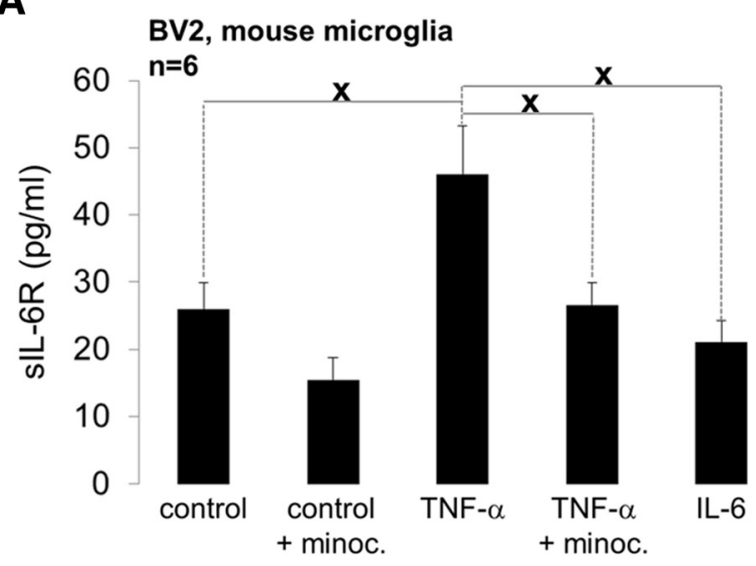

C

BV2, mouse microglia

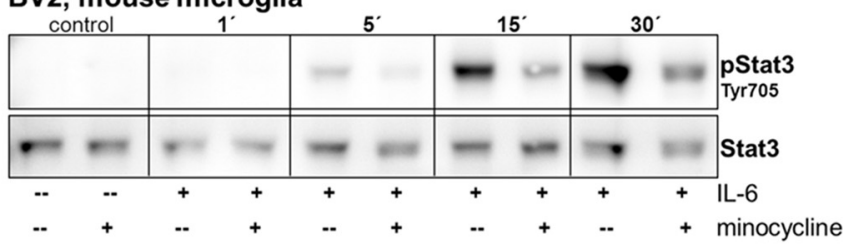

$\mathbf{B}$

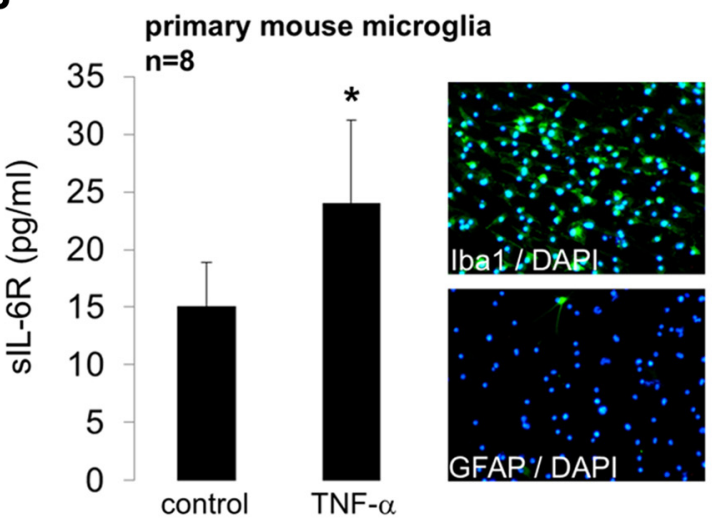

Figure 4. TNF- $\alpha$ interacts with microglia to recruit soluble IL-6 receptor. $A$, Release of IL-6 soluble receptor (sIL6-R) into the supernatant of BV 2 mouse microglia cells within $2 \mathrm{~h}$ of stimulation $(n=6)$. Basal release (control, $26.0 \pm 3.9 \mathrm{pg} / \mathrm{ml}$, mean \pm SEM) decreased insignificantly in the presence of minocycline. TNF- $\alpha$ increased sll-6R release significantly, an effect inhibited by minocycline. There was no additional release of $s \mathrm{IL}-6 \mathrm{R}$ by IL-6. x indicates a significant difference between the indicated groups $(p<0.05$ by $t$ test). $\boldsymbol{B}$, Release of $s \mathrm{LL}-6 \mathrm{R}$ into the supernatant of primary mouse microglial cells within $2 \mathrm{~h}$ $(n=8)$. Basal release (control, $15.1 \pm 3.8 \mathrm{pg} / \mathrm{ml}$, mean \pm SEM) increased significantly with TNF- $\alpha(24.1 \pm 7.2 \mathrm{pg} / \mathrm{ml}, p<0.05$ by Wilcoxon matched-pairs signed-rank test). Right, Comparison of microglial marker (Iba1) and astrocyte marker (GFAP) with all cells (DAPI) shows purity of microglial culture. C, Representative Western blot analysis $(n=3)$ on Stat3 activation (pStat3-Tyr705) in IL-6R-positive BV2 microglia cells (left) and IL-6R-negative SH-SY5Y neuroblastoma cells (right). BV2 cells showed Stat3 activation after IL-6 (classic signaling); SH-SY5Y cells exhibited Stat3 activation after application of IL-6/sLL-6R complex (trans-signaling). Minocycline inhibited Stat3 activation in BV2 cells, but not in SH-SY5Y cells.

responses, we first administered minocycline to the spinal cord for $1 \mathrm{~h}$. Then we added TNF- $\alpha$ in one experimental group and TNF- $\alpha$ plus sIL-6R in the other group. Figure $5 A$ shows that the spinal application of TNF- $\alpha$ after minocycline did not alter significantly the responses of the neurons to mechanical stimulation. However, the addition of TNF- $\alpha$ plus sIL-6R in the other group strongly increased the responses to mechanical stimulation. Therefore, minocycline prevented the increase of the responses by TNF- $\alpha$, but the addition of exogenous sIL-6R to TNF- $\alpha$ and minocycline restored the typ- 
ical TNF- $\alpha$ effect. Neither minocycline alone nor sIL-6R alone changed significantly the responses of the neurons to mechanical stimulation (Fig. $5 B$ ).

TNF- $\alpha$ induces spinal hyperexcitability via IL-6/sIL-6R

Putting together all of the data from the previous experiments, we developed the hypothesis displayed in Figure $6 A$. We propose that TNF- $\alpha$ furthers the release of IL- 6 from neurons and the release of sIL-6R from glial cells. This leads to the formation of IL-6/sIL-6R complexes, which act on the neurons and mediate the TNF- $\alpha$-induced hyperexcitability. In this model, etanercept, which neutralizes TNF- $\alpha$, should prevent the induction of hyperexcitability, as shown previously (König et al., 2014), whereas it should not prevent the effect of IL-6/sIL-6R. Furthermore, the spinal application of minocycline should not inhibit the induction of hyperexcitability induced by application of exogenous IL-6/sIL-6R.

The spinal application of etanercept did not influence the increase of the responses to mechanical stimulation evoked by the spinal application of IL-6/sIL-6R (Fig. 6B). Therefore, the IL-6/sIL-6R complex acts independently of TNF- $\alpha$. Minocycline, preadministered for $1 \mathrm{~h}$, blocked the hyperexcitability evoked by TNF- $\alpha$, but did not block the hyperexcitability evoked by exogenous IL-6/sIL-6R (Fig. 6C). This indicates that IL6 transsignaling acts downstream of TNF- $\alpha$ and microglia functions.

\section{Discussion}

The present study shows that the induction of hypersensitivity of spinal nociceptive neurons in the deep dorsal horn by TNF- $\alpha$ depends significantly on IL-6/sIL-6R signaling acting downstream of TNF- $\alpha$. Sensitization by TNF- $\alpha$ was strongly attenuated by sgp130, which inhibits IL-6 trans-signaling, or by an antibody to IL-6R, whereas sensitization by IL-6/sIL-6R was not blocked by etanercept. Minocycline prevented TNF- $\alpha$-induced sensitization, indicating the involvement of microglial cells. IL- 6 was localized in neurons of the spinal cord and, during peripheral noxious stimulation in the presence of spinal TNF- $\alpha$, IL- 6 was released spinally. IL-6 alone did not induce hyperexcitability, but required the coadministration of sIL-6R. The microglia may serve as an endogenous source of sIL-6R. In a microglial cell line and in primary microglial cells, TNF- $\alpha$ stimulated the release of sIL-6R. The conclusions are displayed in Figure 7.

Although the actions of either TNF- $\alpha$ or IL- 6 on spinal neurons have been explored previously, usually in slice preparations (see below), the necessity of an interaction of cytokines has not been addressed. In the present study, the interaction of spinal TNF- $\alpha$ and

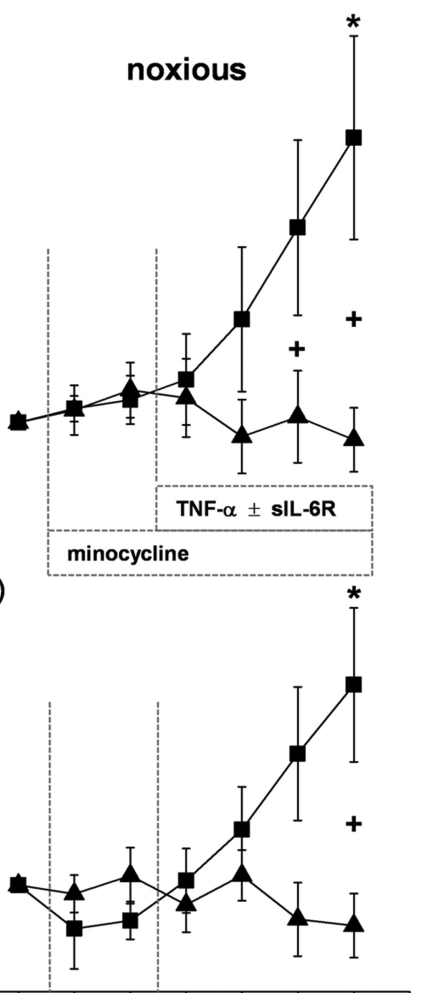

BL $306090120150180 \mathrm{~min}$
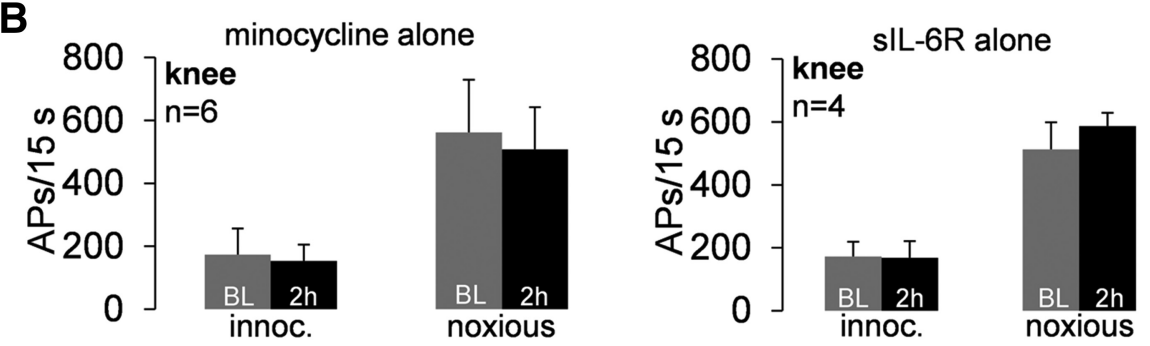

Figure 5. Effect of minocycline on TNF- $\alpha$-induced hyperexcitability. $A$, There were no changes of neuronal responses to mechanical stimulation after application of minocycline only and no increase after subsequent application of minocycline $(n=7)$. Data are shown as the mean number of action potentials per $15 \mathrm{~s}$ (mean APs $/ 15 \mathrm{~s}) \pm$ SEM for intervals of $30 \mathrm{~min}$ Baseline values (in APs/15 s) in the minocycline/TNF- $\alpha$ group: innocuous pressure knee $288.3 \pm 105.2$, noxious pressure $66.8 \pm 113.0$, innocuous pressure ankle $260.9 \pm 69.8$, noxious pressure ankle $482.9 \pm 84.8$. Baseline values (in APs/15 s) in the minocycline/TNF- $\alpha$ /slL-6R group: innocuous pressure knee $42.3 \pm 28.2$, noxious pressure knee $326.1 \pm$ 98.7 , innocuous pressure ankle $112.3 \pm 60.3$, noxious pressure ankle $554.9 \pm 160.5$. Asterisks with arrow indicate the Wilcoxon matched-pairs signed-rank test); plus signs indicate significant difference between the groups at the specific time point $(p<0.05$ by Mann-Whitney $U$ test). BL, Baseline. $B$, Neuronal responses to knee stimulation before (baseline) and $90-120 \mathrm{~min}(2 \mathrm{~h})$ after application of minocycline or slL-6R alone.

IL-6 was explored by using mainly extracellular recordings from spinal cord neurons in vivo. This integrative approach allowed us to monitor responses from single neurons to repetitive natural stimulation at innocuous and noxious stimulus intensities for several hours, to study the release of mediators from the intact spinal cord during natural stimulation, and to apply compounds to an area in which the neurons are recorded. We focused on neurons in the deep dorsal horn because neurons with consistent responses to stimulation of the joint can be identified there (Vazquez et al., 2012; König et al., 2014).

A key finding was the attenuation of the TNF- $\alpha$ effect by sgp 130 or an antibody to IL-6R, which binds to sIL-6R and gp 80 of rat, thus showing specifically the importance of IL-6 signaling. Although this 
A

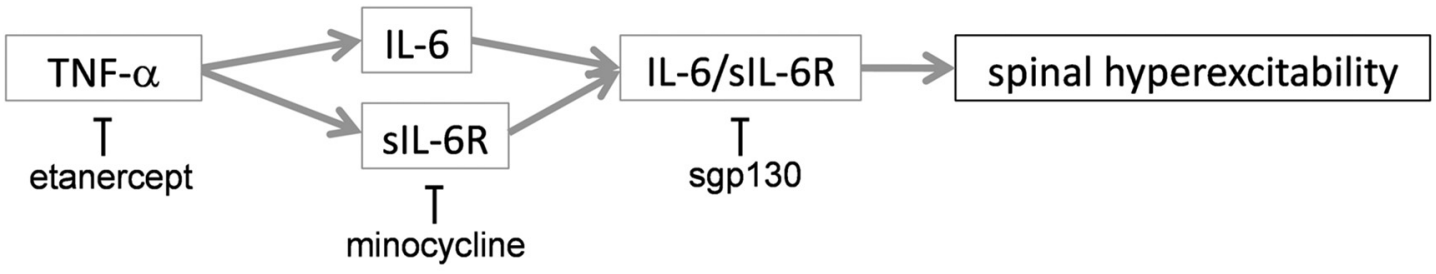

B

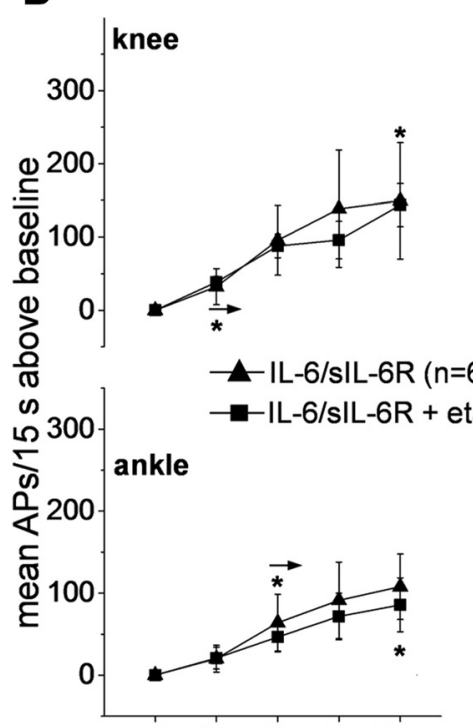

BL $30 \quad 60 \quad 90 \quad 120 \mathrm{~min}$

\begin{abstract}
innocuous
\end{abstract}
noxious
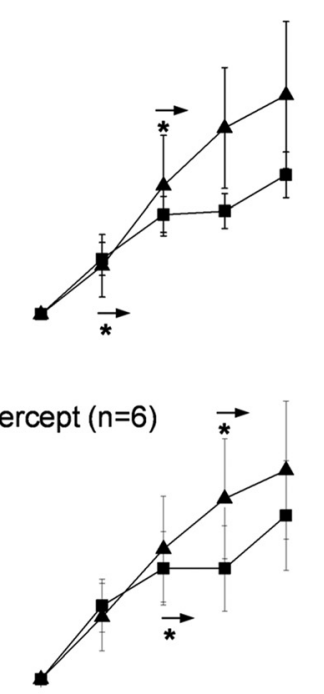

BL $30 \quad 60 \quad 90 \quad 120 \mathrm{~min}$
C

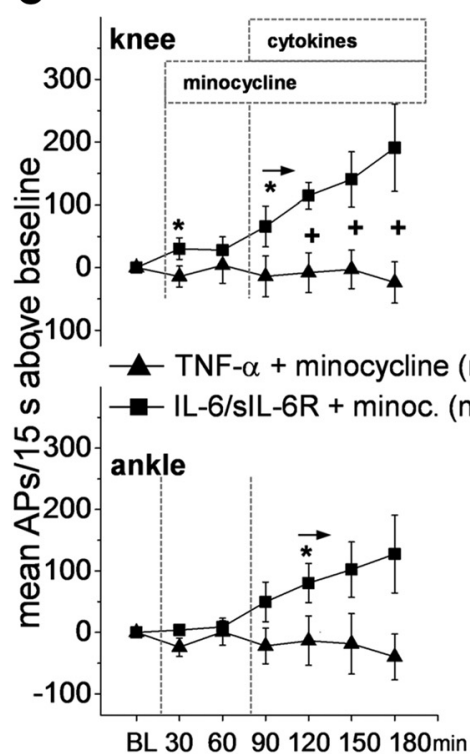

noxious

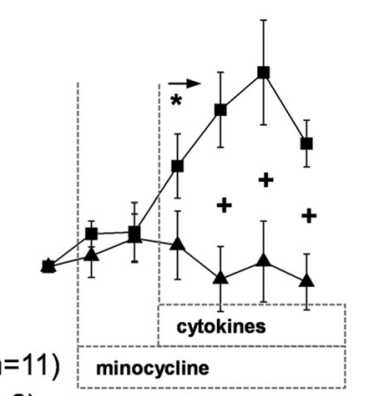

$$
n=8)
$$

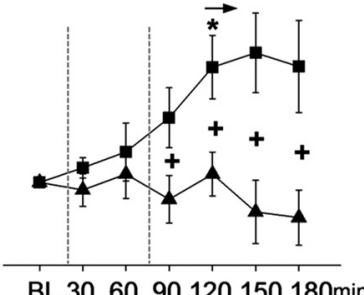

Figure 6. Induction of hyperexcitability of deep dorsal horn neurons by TNF- $\alpha$ via IL-6/sIL-6R. A, Hypothetical flow chart of an upstream function of TNF- $\alpha$ initiating the release of IL-6 and sIL-6R from different sources to form the downstream IL-6/sL-6R complex for IL-6 trans-signaling. Indicated are the action sites of specific inhibitors. $B$, Increases of neuronal responses to mechanical stimulation by spinal application of IL-6/sL-6R $(n=6)$ and spinal application of IL-6/sL-6R plus etanercept $(n=6)$ for $2 \mathrm{~h}$, shown as mean number of action potentials per $15 \mathrm{~s}$ (mean APs/15 s) \pm SEM for intervals of $30 \mathrm{~min}$. Baseline values (in APs/15 s) in the IL-6/slL-6R group: innocuous pressure knee 154.5 \pm 23.2 , noxious pressure knee $357.8 \pm 43.1$, innocuous pressure ankle 67.0 \pm 28.7 , noxious pressure ankle $470.4 \pm 80.7$. Baseline values (in APs/15 s) in the IL-6/slL-6R plus etanercept group: innocuous pressure knee $81.6 \pm 47.8$, noxious pressure knee $298.3 \pm 84.6$, innocuous pressure ankle $53.8 \pm 44.0$, noxious pressure ankle $322.7 \pm 135.4$. C, Increases of neuronal responses to mechanical stimulation by spinal application of TNF- $\alpha$ plus minocycline $(n=11)$ or IL-6/slL-6R plus minocycline $(n=8)$ for $2 \mathrm{~h}$, shown as mean number of action potentials per $15 \mathrm{~s}$ (mean APs $/ 15 \mathrm{~s}$ ) \pm SEM for intervals of 30 min. Baseline values (in APs/15 s) in the TNF- $\alpha$ plus minocycline group: innocuous pressure knee $288.3 \pm 105.2$, noxious pressure knee $636.8 \pm 113.0$, innocuous pressure ankle $260.9 \pm 69.8$, noxious pressure ankle $482.9 \pm 84.8$. Baseline values (in APs/15 s) in the IL-6/sIL-6R plus minocycline group: innocuous pressure knee $98.4 \pm 34.4$, noxious pressure knee $292.5 \pm 53.1$, innocuous pressure ankle $56.4 \pm 36.1$, noxious pressure ankle $261.2 \pm 54.4$. Asterisks with arrow indicate the start of significant increases of responses or significant increase of responses at the specific time point $(p<0.05$ by Wilcoxon matched-pairs signed-rank test); plus signs indicate significant difference between the groups at the specific time point ( $p<0.05$ by Mann-Whitney $U$ test). BL, Baseline.

effect was strong, it was not complete because the responses to innocuous pressure applied to the knee and ankle still showed a small significant increase. This may reflect the activation of TNF receptors expressed in neurons (Probert, 2015). In isolated spinal cord slices, TNF- $\alpha$ increased the frequency of spontaneous EPSPs, as well as AMPA- and NMDA-induced currents in dorsal horn neurons (Kawasaki et al., 2008; Spicarova et al., 2011; Zhang et al., 2011), and TNF- $\alpha$ was found to facilitate excitation by inhibiting superficial inhibitory GABAergic dorsal horn neurons (Zhang and Dougherty, 2011; Zhang et al., 2011). Importantly, in the present in vivo study, we found a significant increase of the spinal release of IL- 6 during the development of hyperexcitability evoked by TNF- $\alpha$. We assume that IL-6 was mainly released from neurons upon stimulation, a possibility suggested previously (Ringheim et al., 1995; Jüttler et al., 2002). In the spinal cord of the healthy rat, we localized IL-6 mainly in neurons (Arruda et al., 1998) and did not find IL-6 expression in microglial cells, corroborating other studies (Guptarak et al., 2013). However, in advanced pain states, IL-6 may also be released from activated glia (Guptarak et al., 2013; Ji et al., 2013). Interestingly, in the liver, the release of TNF- $\alpha$ from Kupffer cells caused a massive release of IL-6 within $2-3 \mathrm{~h}$, thus also showing activation of IL-6 signaling by TNF- $\alpha$ (Schmidt-Arras and Rose-John, 2016).

All IL- 6 effects are mediated by activation of the signal transduction unit gp130, which is expressed ubiquitously. The gp130 transduction unit is either activated by binding of IL- 6 to IL-6R in the membrane (gp80) or by IL-6/sIL-6R complexes, allowing IL-6 effects on cells without membrane-bound gp 80 (trans-signaling). Notably, trans-signaling is only possible if IL-6/sIL-6R complexes reach a concentration higher than that of endogenous sgp130 that neutralizes the complexes (Rose-John, 2012). Therefore, the actions of IL-6 on many cells depend on three factors: IL-6, sIL-6R, and endogenous sgp130. In the present experiments, the administration of IL- 6 alone did not change the neuronal responses to mechanical stimulation, indicating that not enough IL-6/sIL-6R complexes were formed to overcome the neutralization by sgp 130 . IL- 6 on its own could only act on membrane-bound gp 80 , which is mainly restricted to microglia or cerebrovascular endothelial cells (Lin and Levison, 2009; Campbell et al., 2014; Rothaug et al., 2016). However, interestingly, IL-6 itself did not enhance the release of sIL-6R from microglia in vitro. Therefore, the availability of sIL-6R appears to be the limiting 


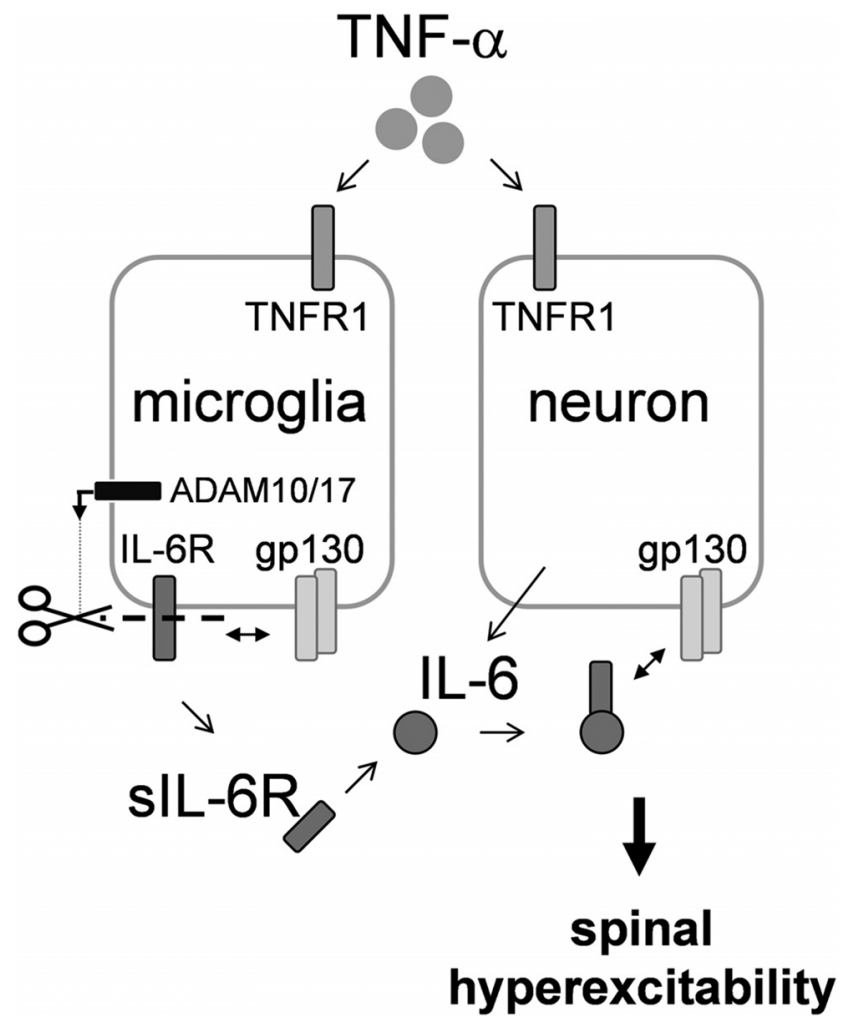

Figure 7. Model of the cooperation of TNF- $\alpha$ and IL-6in the generation of spinal hyperexcitability. TNF- $\alpha$ leads to IL-6 release mainly from neurons and acts on microglia to provide sIL-6R for IL-6 trans-signaling by ADAM10/17-protease-dependent cleavage of IL-6R, which is not present in neurons. Interaction of IL-6-bound IL-6R or IL-6/sIL-6R complex with ubiquitously expressed and homodimerized gp 130 is required for IL-6 signaling.

factor to the formation of IL-6/sIL-6R complexes sufficient to overcome the inhibition by sgp130. In contrast, the application of IL-6/sIL-6R to the spinal cord caused spinal hyperexcitability, confirming our previous results (Vazquez et al., 2012) showing that the IL-6 effects on neuronal excitability are mainly dependent on trans-signaling.

The starting point of the present study was the observation that the induction of hyperexcitability by TNF- $\alpha$ was blocked by sgp130. Therefore, the experiments focused on the question of how TNF- $\alpha$ is related to IL- 6 signaling. We propose that TNF- $\alpha$ furthers the release of IL- 6 from neurons and stimulates the release of sIL-6R from microglia to overcome endogenous sgp 130. These conclusions are based on two sets of data. First, BV2 cells, which express membrane-bound gp 80 similar to primary microglia (Hsu et al., 2015), and primary microglial cell cultures showed a basal release of sIL-6R. The sIL-6R release was enhanced significantly by TNF- $\alpha$. Minocycline, applied to BV2 cells, blocked the effect of TNF- $\alpha$. The monitoring of Stat 3 activation in BV2 cells and in the neuronal cell line SH-SY5Y showed that minocycline inhibited Stat 3 activation by IL- 6 in BV2 cells, but not in the neuronal cell line stimulated with IL-6/sIL-6R, indicating that minocycline acted on microglia, but not on neurons. Interestingly, IL- 6 itself did not enhance the release of sIL-6R from microglia. Second, the increase of the neuronal responses to mechanical stimuli by TNF- $\alpha$ was prevented by minocycline, which inhibits microglia rapidly (Sorge et al., 2015), indicating that microglial activation is involved in TNF- $\alpha$ induced sensitization. The application of minocycline alone did not alter the magnitude of the neuronal responses to mechanical stimulation significantly, showing that unspecific effects of minocycline were negligible. However, the induction of hyperexcitability by TNF- $\alpha$ in the presence of minocycline was restored by coapplication of exogenous sIL-6R, thus bypassing the block of glial cell activation. It is important to note that the increase of the neuronal responses by IL-6/sIL-6R was not blocked by minocycline (corresponding to the failure of minocycline to inhibit Stat3 activation by IL-6/sIL-6R). Furthermore, the application of sIL-6R alone had no effect on neuronal responses, supporting the role of TNF- $\alpha$ in providing sufficient IL- 6 .

If IL-6/sIL-6R acts downstream of TNF- $\alpha$, then etanercept should inhibit the effect of TNF- $\alpha$, but not the effect of IL-6/sIL-6R, on neuronal responses. Indeed, coapplication of etanercept with TNF- $\alpha$ prevented the increase of the neuronal responses (König et al., 2014), but the spinal responses to knee stimulation were increased upon coapplication of etanercept and IL-6/sIL-6R.

In a previous study, we found a rapid increase of the spinal release of IL-6 during the development of kaolin/carrageenan (K/C)-induced inflammation (Vazquez et al., 2012). Therefore, the question arises of whether spinal TNF- $\alpha$ is at all necessary to further spinal hyperexcitability. Importantly, either etanercept or an antibody to TNFR1 prevented the generation of spinal hyperexcitability during the development of inflammation (König et al., 2014). Here, we show that TNF- $\alpha$ activates the microglia to provide sIL-6R, which allows IL-6/sIL-6R trans-signaling. These novel data explain why, in our previous studies, the spinal application of either etanercept or sgp130 prevented the development of spinal hyperexcitability during the development of acute inflammation in the knee joint. The endogenous source of TNF- $\alpha$ is likely to be the microglia (Hanisch, 2002; Ji et al., 2013).

However, in the previous studies, neither spinally applied sgp130 nor spinally applied etanercept reversed within $1-2 \mathrm{~h}$ the established spinal hyperexcitability upon established K/C inflammation (Vazquez et al., 2012; König et al., 2014). In primary afferent sensory neurons, we found that mechanical hyperexcitability induced by IL-6/sIL-6R is more difficult to reverse than mechanical hyperexcitability induced by TNF- $\alpha$ (Brenn et al., 2007; Richter et al., 2010). Therefore, the critical involvement of IL-6/sIL-6R signaling in the spinal effects of TNF- $\alpha$ may explain why neither sgp130 nor etanercept reversed the hyperexcitability of deep dorsal horn neurons once established. This is also consistent with the induction of nociceptive neuronal priming evoked by IL-6 (Melemedjian et al., 2010).

In sum, the present study shows how two important cytokines in the spinal cord interact in the generation of inflammationevoked spinal hyperexcitability, an important mechanism of clinically significant pain, for example, in the musculoskeletal system (see discussion in Phillips and Clauw, 2013). Because other cytokines such as IL-1 $\beta$ are also expressed in the spinal cord (McMahon and Malcangio, 2009), it is likely that further interactions between cytokines may be identified. The understanding of interactions of cytokines (and other mediators) could be important for the development of therapeutical strategies. Because TNF- $\alpha$, IL- 6 , and other cytokines are expressed throughout the CNS (Erta et al., 2012; Probert, 2015; Rothaug et al., 2016), such data may also be relevant in brain regions.

\section{References}

Arruda JL, Colburn RW, Rickman AJ, Rutkowski MD, DeLeo JA (1998) Increase of interleukin- 6 mRNA in the spinal cord following peripheral nerve injury in the rat: potential role of IL- 6 in neuropathic pain. Mol Brain Res 62:228-235. CrossRef Medline

Bao L, Zhu Y, Elhassan AM, Wu Q, Xiao B, Zhu J, Lindgren JU (2001) Adjuvant- 
induced arthritis: IL-1 beta, IL-6 and TNF-alpha are up-regulated in the spinal cord. Neuroreport 12:3905-3908. CrossRef Medline

Brenn D, Richter F, Schaible HG (2007) Sensitization of unmyelinated sensory fibers of the joint nerve to mechanical stimuli by interleukin- 6 in the rat: an inflammatory mechanism of joint pain. Arthritis Rheum 56: 351-359. CrossRef Medline

Campbell IL, Erta M, Lim SL, Frausto R, May U, Rose-John S, Scheller J, Hidalgo J (2014) Trans-signaling is a dominant mechanism for the pathogenic actions of interleukin-6 in the brain. J Neurosci 34:25032513. CrossRef Medline

Cao H, Zhang YQ (2008) Spinal glial activation contributes to pathological pain states. Neurosci Biobehav Rev 32:972-983. CrossRef Medline

Christianson CA, Corr M, Firestein GS, Mobargha A, Yaksh TL, Svensson CI (2010) Characterization of the acute and persistent pain state present in $\mathrm{K} / \mathrm{BxN}$ serum transfer arthritis. Pain 151:394-403. CrossRef Medline

Clark AK, Yip PK, Grist J, Gentry C, Staniland AA, Marchand F, Dehvari M, Wotherspoon G, Winter J, Ullah J, Bevan S, Malcangio M (2007) Inhibition of spinal microglial cathepsin $S$ for the reversal of neuropathic pain. Proc Natl Acad Sci U S A 104:10655-10660. CrossRef Medline

Erta M, Quintana A, Hidalgo J (2012) Interleukin-6, a major cytokine in the central nervous system. Int J Biol Sci 8:1254-1266. CrossRef Medline

Garbers C, Jänner N, Chalaris A, Moss ML, Floss DM, Meyer D, Koch-Nolte F, Rose-John S, Scheller J (2011) Species specificity of ADAM10 and ADAM17 proteins in interleukin-6 (IL-6) trans-signaling and novel role of ADAM10 in inducible IL-6 receptor shedding. J Biol Chem 286:1480414811. CrossRef Medline

Garrido-Mesa N, Zarzuelo A, Gálvez J (2013) Minocycline: far beyond an antibiotic. Br J Pharmacol 169:337-352. CrossRef Medline

Guptarak J, Wanchoo S, Durham-Lee J, Wu Y, Zivadinovic D, PaulucciHolthauzen A, Nesic O (2013) Inhibition of IL-6 signaling: a novel therapeutic approach to treating spinal cord injury pain. Pain 154:1115-1128. CrossRef Medline

Hanisch UK (2002) Microglia as a source and target of cytokines. Glia 40: 140-155. CrossRef Medline

Henn A, Lund S, Hedtjärn M, Schrattenholz A, Pörzgen P, Leist M (2009) The suitability of BV2 cells as alternative model system for primary microglia cultures or for animal experiments examining brain inflammation. ALTEX 26:83-94. Medline

Hsu MP, Frausto R, Rose-John S, Campbell IL (2015) Analysis of IL-6/ gp130 family receptor expression reveals that in contrast to astroglia, microglia lack the oncostatin $\mathrm{M}$ receptor and functional responses to oncostatin M. Glia 63:132-141. CrossRef Medline

Ji RR, Berta T, Nedergaard M (2013) Glia and pain: is chronic pain a gliopathy? Pain 154:S10-S28. CrossRef Medline

Jostock T, Müllberg J, Ozbek S, Atreya R, Blinn G, Voltz N, Fischer M, Neurath MF, Rose-John S (2001) Soluble gp130 is the natural inhibitor of soluble interleukin-6 receptor transsignaling responses. Eur J Biochem 268:160-167. CrossRef Medline

Jüttler E, Tarabin V, Schwaninger M (2002) Interleukin-6 (IL-6): a possible neuromodulator induced by neuronal activity. Neuroscientist 8:268-275. Medline

Kawasaki Y, Zhang L, Cheng JK, Ji RR (2008) Cytokine mechanisms of central sensitization: distinct and overlapping role of interleukin-1beta, interleukin-6, and tumor necrosis factor-alpha in regulating synaptic and neuronal activity in the superficial spinal cord. J Neurosci 28:5189-5194. CrossRef Medline

König C, Zharsky M, Möller C, Schaible HG, Ebersberger A (2014) Involvement of peripheral and spinal tumor necrosis factor alpha in spinal cord hyperexcitability during knee joint inflammation in rats. Arthritis Rheum 66:599-609. CrossRef Medline

Latrémolière A, Mauborgne A, Masson J, Bourgoin S, Kayser V, Hamon M, Pohl M (2008) Differential implication of proinflammatory cytokine interleukin-6 in the development of cephalic versus extracephalic neuropathic pain in rats. J Neurosci 28:8489-8501. CrossRef Medline

Lin HW, Levison SW (2009) Context-dependent IL-6 potentiation of interferon- gamma-induced IL-12 secretion and CD40 expression in murine microglia. J Neurochem 111:808-818. CrossRef Medline

Marchand F, Perretti M, McMahon SB (2005) Role of the immune system in chronic pain. Nat Rev Neurosci 6:521-532. Medline

McMahon SB, Malcangio M (2009) Current challenges in glia-pain biology. Neuron 64:46-54. CrossRef Medline

Melemedjian OK, Asiedu MN, Tillu DV, Peebles KA, Yan J, Ertz N, Dussor GO, Price TJ (2010) IL-6 and NGF-induced rapid control of protein synthesis and nociceptive plasticity via convergent signaling to the eIF4F complex. J Neurosci 30:15113-15123. CrossRef Medline

Milligan ED, Watkins LR (2009) Pathological and protective roles of glia in chronic pain. Nat Rev Neurosci 10:23-36. CrossRef Medline

Neher JJ, Emmrich JV, Fricker M, Mander PK, Théry C, Brown GC (2013) Phagocytosis executes delayed neuronal death after focal brain ischemia. Proc Natl Acad Sci U S A 110:E4098-4107. CrossRef Medline

Nowell MA, Richards PJ, Horiuchi S, Yamamoto N, Rose-John S, Topley N, Williams AS, Jones SA (2003) Soluble IL-6 receptor governs IL-6 activity in experimental arthritis: blockade of arthritis severity by soluble glycoprotein 130. J Immunol 171:3202-3209. CrossRef Medline

Padberg F, Feneberg W, Schmidt S, Schwarz MJ, Körschenhausen D, Greenberg BD, Nolde T, Müller N, Trapmann H, König N, Möller HJ, Hampel H (1999) CSF and serum levels of soluble interleukin-6 receptors (sIL-6R and sgp130), but not of interleukin-6 are altered in multiple sclerosis. J Neuroimmunol 99:218-223. CrossRef Medline

Phillips K, Clauw DJ (2013) Central pain mechanisms in the rheumatic diseases. Arthritis Rheum 65:291-302. CrossRef Medline

Probert L (2015) TNF and its receptors in the CNS: The essential, the desirable and the deleterious effects. Neuroscience 302:2-22. CrossRef Medline

Raghavendra V, Tanga FY, DeLeo JA (2004) Complete Freunds adjuvantinduced peripheral inflammation evokes glial activation and proinflammatory cytokine expression in the CNS. Eur J Neurosci 20:467-473. CrossRef Medline

Richter F, Natura G, Löser S, Schmidt K, Viisanen H, Schaible HG (2010) Tumor necrosis factor- $\alpha$ (TNF- $\alpha$ ) causes persistent sensitization of joint nociceptors for mechanical stimuli. Arthritis Rheum 62:3806-3814. CrossRef Medline

Ringheim GE, Burgher KL, Heroux JA (1995) Interleukin-6 mRNA expression by cortical neurons in culture: evidence for neuronal sources of interleukin-6 production in the brain. J Neuroimmunol 63:113-123. CrossRef Medline

Rose-John S (2012) IL-6 trans-signaling via the soluble IL-6 receptor: importance for the pro-inflammatory activities of IL-6. Int J Biol Sci 8: 1237-1247. CrossRef Medline

Rothaug M, Becker-Pauly C, Rose-John S (2016) The role of interleukin-6 signaling in the nervous system. Biochim Biophys Acta 1863:1218-1227. CrossRef Medline

Sagar DR, Burston JJ, Hathway GJ, Woodhams SG, Pearson RG, Bennett AJ, Kendall DA, Scammell BE, Chapman V (2011) The contribution of spinal glial cells to chronic pain behaviour in the monosodium iodoacetate model of osteoarthritic pain. Mol Pain 7:88. CrossRef Medline

Santello M, Volterra A (2012) TNF $\alpha$ in synaptic function: switching gears. Trends Neurosci 35:638-647. CrossRef Medline

Schmidt-Arras D, Rose-John S (2016) IL-6 pathway in the liver: From pathophysiology to therapy. J Hepatol 64:1403-1415. CrossRef Medline

Sorge RE et al. (2015) Different immune cells mediate mechanical pain hypersensitivity in male and female mice. Nat Neurosci 18:1081-1083. CrossRef Medline

Spicarova D, Nerandzic V, Palecek J (2011) Modulation of spinal cord synaptic activity by tumor necrosis factor alpha in a model of peripheral neuropathy. J Neuroinflammation 8:177. CrossRef Medline

Turnquist B, Leverentz M, Swanson E (2004) Neural spike classification using parallel selection of all algorithm parameters. J Neurosci Methods 137:291-298. CrossRef Medline

Vazquez E, Kahlenbach J, Segond von Banchet G, König C, Schaible HG, Ebersberger A (2012) Spinal interleukin-6 is an amplifier of arthritic pain in the rat. Arthritis Rheum 64:2233-2242. CrossRef Medline

Walker F, Zhang HH, Matthews V, Weinstock J, Nice EC, Ernst M, Rose-John S, Burgess AW (2008) IL6/sIL6R complex contributes to emergency granulopoietic responses in G-CSF- and GM-CSF-deficient mice. Blood 111:3978-3985. CrossRef Medline

Woolf CJ, Salter MW (2000) Neuronal plasticity: increasing the gain in pain. Science 288:1765-1769. CrossRef Medline

Yrjänheikki J, Keinänen R, Pellikka M, Hökfelt T, Koistinaho J (1998) Tetracyclines inhibit microglial activation and are neuroprotective in global brain ischemia. Proc Natl Acad Sci U S A 95:15769-15774. CrossRef Medline

Zhang H, Dougherty PM (2011) Acute inhibition of signalling phenotype of spinal GABAergic neurons by tumour necrosis factor. J Physiol 589: 4511-4526. CrossRef Medline

Zhang L, Berta T, Xu ZZ, Liu T, Park JY, Ji RR (2011) TNF-alpha contributes to spinal cord synaptic plasticity and inflammatory pain: distinct role of TNF receptor subtypes 1 and 2. Pain 152:419-427. CrossRef Medline 